\title{
STUDY OF LOCAL TOURIST SATISFACTION IN A RURAL DESTINATION AT MOUNT MULU NATIONAL PARK IN MIRI, SARAWAK
}

\author{
ZALIHA ZAINUDDIN*, ZALEHA MOHAMED AND HAROLD LOLING
}

Department of Tourism Management, Faculty of Business, Economics and Social Development, Universiti Malaysia Terengganu, Kuala Nerus, Terengganu, Malaysia

*Corresponding author: zaliha.z@umt.edu.my

http://doi.org/10.46754/umtjur.2021.04.0011

\begin{abstract}
Tourism is associated with leisure and travelling, and is considered one of the fastest growing sectors that contribute significantly to the country's economy, as well as bringing benefits directly to local communities. The Rural Tourism Master Plan was established in 2001, which defines rural tourism as an attraction that offers visitors the opportunity to experience Malaysia's traditional culture and heritage away from urban areas. This study focuses on such tourism in the Gunung Mulu National Park, a famous natural park comprising underground caves, virgin rainforests and highlands. This research uses a quantitative approach with a random sampling technique because the procedure to select a unit for inclusion in a sample is much easier, quicker and cheaper. A questionnaire is distributed via Google Form to 500 local tourists who visited the park. The results of this research may be useful in marketing the Gunung Mulu National Park worldwide, besides finetuning programmes to attract tourists to the national park.
\end{abstract}

Keywords: Rural tourism, service quality, tourist satisfaction, Rural Tourism Master Plan, Gunung Mulu National Park

\section{Introduction}

Tourism is a vital driving force in alleviating poverty and regional disparities, especially in emerging destinations through enhancement of employment prospects and national income. Nations are always enhancing their tourist attractions, besides adding new destinations and products. Therefore, it is a prominent challenge for many destinations to maintain and strengthen their position in an ever-competitive global marketplace. For this reason, the measurement of destination competitiveness has become fundamental in the strategic planning of tourism development. In other words, the evaluation of competitiveness is a decisive factor for governments to create policies and allocate resources in developing various tourist destinations in the country.

In the recent years, competitiveness has become a familiar concept to describe sustainable development in travel and tourism (Mendola \& Volo, 2015). The competitiveness of tourist destinations becomes increasingly important to countries that intend to capture a significant share of the rapidly growing tourist market. This is particularly important for countries that rely heavily on travel and tourism for revenue (Croes \& Rivera, 2010). As global competition increases, countries operating in the international tourism market are continuously forced to search for the best way of providing customer satisfaction (Turanlı \& Guneren, 2003).

In tourism, the determining factors of a country's competitiveness lie in its comparative and competitive advantage (Croes \& Kubickova, 2013). The factors that determined comparative advantage are mostly related to the natural characteristics of the tourist destination, such as image, climate, countryside, cultural wealth and distance from the tourists' country of origin. Competitive advantage, on the other hand, is determined by factors that range from price level in the structure of tourism, to the management 
of companies and characteristics of the environment in which they operate, including the quality of tourism products, sustainability, tourist satisfaction, infrastructure and human capital.

Due to the different nature of destinations or the purpose/types of tourism activities, it's hard to measure, evaluate and compare between destinations, as in many cases, because each is unique and cannot be considered identical (Prebensen et al., 2014). Therefore, to analyze the competitiveness of tourist destinations, it is necessary to investigate the tourists' level of satisfaction and tourism image as a paradigm of competitiveness. This concept is imperative because destination competitiveness is strongly linked to tourist satisfaction, their repeat purchasing behaviour, destination image, consumer loyalty and word-of-mouth recommendation (Vasilevich \& Czetyrbok, 2015).

Building an appealing portfolio of tourism products and services requires concerted effort to manage and promote tourist destinations at the local level. In other words, the development, marketing image and strategic planning of the destination may be one of the key sources of competitive advantage as well as one of the key elements of the tourist destination choice process (Gallarza et al., 2002; Lee et al., 2006; Kavoura, 2014). Therefore, in order to successfully market a destination, there is a need to change the focus and shift it from a destination to tourist per se.

The growth of tourism in Malaysia is the result of various marketing efforts by the government and other stakeholders. Therefore, it is not surprising if many states and local communities nationwide venture into the industry themselves as a niche market is vital to rejuvenate and sustain local economies. Before highlighting tourism in Malaysia, it is worth getting an overview on global tourism. Tourism is renowned a leading service industry that hastens globalisation and directly supports the income of poor communities (Esmail, 2016; Ranabhat, 2015; Ekanayake \& Long, 2012). According to the World Travel and Tourism
Council (2016), the total contribution of travel and tourism to the global economy was US\$7.17 trillion in 2015, which comprised an average of 9.8 per cent of the world gross domestic product. This record proves that tourism is a profitable industry and wealth creator. In fact, this industry not only generated considerable foreign exchange revenues, but also contributed to the overall socio-economic development and employment prospects of most countries (Giap et al., 2016; Nurbaeti et al., 2016). The World Tourism Organization (2015) had predicted that worldwide visitor arrivals would exceed one billion by 2017 , driven by a growing population, longer life expectancy, migration and change in family structures.

In addition, the expansion of middle-class citizens in emerging economies, most notably China and India, have fuelled tourism growth. With these changes, the effects on the nature of travel consumption, as well as opportunities and challenges for the industry, have become apparent (WTO 2016). The demand for tourism has increased and new destinations have emerged, and competition in the sector has intensified (Crouch 2011; Getz \& Brown, 2006).

Tourism is defined as an industry associated with leisure and travel (Cunha \& Cunha, 2005), and is considered one of the world's top and fastest growing sectors that contributes significantly to the country's growth, as well as bringing economic benefits to local communities (Osman \& Sentosa, 2013). It has experienced tremendous growth over the past decades, and visitors are now seeking places of solitude, away from bustling urban centres, to retreat, relax and relieve stress (Lin \& Yeh, 2013).

Thus, rural tourism has attracted attention from governments, non-governmental organizations (NGOs) and industry players because of its potential (Egbali et al., 2011). Ultimately, the quality of tourism in Malaysia must attain minimum standards of satisfaction if repeated visits are expected to help the nation achieve its objectives. Rural tourism in Malaysia is growing with its multicultural and biodiversity advantages to become an important 
segment of the economy (Lo et al., 2012). The states of Sabah and Sarawak have some of Southeast Asia's best ecotourism destinations (Lifestyle Asia, 2012). Most of these worldclass destinations are in the rural landscape, with attractions and activities generally occurring in agricultural or non-urban settings (Lanea, 1994; Frochot, 2005).

The concept was first introduced by the Malaysian government in the Seventh Malaysian Plan (1996-2000) to bring development to rural areas in the country. The Rural Tourism Master Plan was drawn up in 2001 and it defined rural tourism as an opportunity to visit rural attractions to experience Malaysia's culture and heritage, thus providing local communities with socio-economic benefits.

Some of the significant contributions of rural tourism are socio-cultural development, and conservation and enhancement of natural and built environment and infrastructure. Rural destinations are less frequented by visitors than cities or holiday resorts. They have more to offer compared with urban destinations as they are vast, less crowded, peaceful and tranquil - all the qualities that tourists are intensively searching for.

As customer satisfaction is a determinant of quality management, hence, understanding the perception of customers and what they expect is a major challenge for rural destinations. Scholars have described quality of service in several ways. Service quality is a comparison of the customers' expectations and perceptions with the actual service they received (Grönroos, 1984; Parasuraman et al., 1985). A study by Roest and Pieters (1997) defined the quality of service as a relativistic and cognitive difference between experiential norms and performance on service benefits. Service quality is often seen as an attitude reflecting an overall long-run assessment (Cronin \& Taylor, 1994; Hoffman \& Bateson, 2001).

Cai (2009) noted that delivering quality goods and services to consumers is a must owing to heavy global competition. Quality is usually characterised in terms of customer or stakeholder satisfaction, and one of the determinants of an organization's performance is how customers regarded the resulting service quality as the main driver of perceived value (Collart, 2000; Kumar et al., 2009). Sigala and Christou (2006) assumed that service organizations have changed at both macro and micro-levels, and that consumers are becoming less loyal, but more receptive and discerning, in terms of quality. Hence, satisfying the needs of customers is vital to the survival of a business. According to Ganeshasundaram and Henley (2007), focusing on market needs is important as it is a prerequisite for successful business (Barabba, 1995) and meeting customer needs is a distinctive feature of successful businesses (Stevens et al., 1997).

This study focuses on local tourist satisfaction in visiting the Gunung Mulu National Park, which is 246 kilometres from the city of Miri, Sarawak, Malaysia. Located in Borneo, Gunung Mulu National Park encompasses caves and karst formations in 85,671 hectares of mountainous equatorial rainforest setting. Its height above sea level ranges from $27 \mathrm{~m}$ on the floodplains to $2,377 \mathrm{~m}$ at the summit of Gunung Mulu. The Gunung Mulu National Park was gazetted by the state government in 1974 and in 2000, it was declared a World Heritage Area by the United Nations Educational, Scientific and Cultural Organiation.

\section{Problem Statement}

The Gunung Mulu National Park is a nature reserve that is home to numerous species of flora and fauna. In 2013, the number of international tourist arrivals at the park was 12,871, and locals was 6,286. The following year, they increased to 13,635 and 6,549 , respectively. The data shows that local tourists visiting Gunung Mulu National Park was lower than international tourists. This was probably due to the park's location in the state's backwaters, where accessibility is limited. This discourages local tourists from visiting the park as the cost is expensive, whereas international tourists are 
probably prepared to pay extra to enjoy the natural beauty that is not available in their home country. The study focuses on three objectives listed below:

1. To study the local tourist satisfaction in Gunung Mulu National Park, Miri, Sarawak.

2. To examine the local tourist experience at the park.

3. To study the motive that drives local tourists to choose rural tourism.

\section{Significance of Research}

The data obtained will describe the quality of tourism in a remote destination in Malaysia. This will provide some kind of overview on the satisfaction of local tourists in supporting the growth of rural tourism. On the economic impact, this study may serve as a guide for tourism players to focus and invest on the type of service that tourists are looking for.

Finally, it will create awareness on the need to conserve resources and biodiversity in the natural park, which will then make tourism in the destination sustainable. It also, protect the nature area from the damage that cause by development and activity of tourism. Policymakers may use the findings to develop standards or regulations to make improve tourism products and protect the park from being overexploited.

\section{Literature Review}

\section{Rural Tourism}

Rural tourism is a countryside activity that is known as one of Malaysia's priority rural development tools (Liu, 2006). It is known that tourism has contributed to the development of individual welfare (local communities), traveller's experience and income for the country (Peptenatu et al., 2009). A study has identified destination image as one of the main challenges in Malaysia's tourism industry (Phang et al., 2009). Thus, marketing strategies should emphasise the tourists' experience at the tourism destination. Some studies have highlighted the importance of the environmental component to ensure sustainability (Hanafiah \& Zulkifly, 2019) and development of a competitive strategy (Kim, 2012).

Moreover, major cultural and heritage attractions (eg. handicraft, cultural amenities) also play a pivotal role in rural tourism (Rahmani et al.,2013). Throughout this study, rural tourism is described as a secluded destination that is largely dependent on the natural environment and engages with various forms of local activities based on the preservation of historical heritage, customs and traditions, as well as different arts and cultures of local communities that allow tourists to enjoy natural experiences (Ramakumar \& Rajashree, 2008).

Past researchers (Chen \& Tsai, 2007; Dmitrović et al., 2009; Huang, 2011; Jamaludin et al. 2012; Kumra, 2008; Rajesh, 2013; Zhu, 2011) had never ruled out problems in quality of service. Therefore, providing a good experience has become the most critical component in building tourist loyalty with a long-term role in today's highly competitive market climate (Said et al., 2013; Shonk, 2006).

\section{Concept of Tourist Satisfaction}

Baker and Crompton (2000) suggested that "tourism satisfaction" is the tourists' emotional state after a visiting experience. This is confirmed by Khuong and Luan (2015), who noted that the degree to which a product or service fulfils a person's wishes is significant in assessing the feeling of satisfaction, and this must be included in calculating the level of satisfaction. In addition, Bigné et al. (2001) argued that destination image will influence expectations ahead of an actual visit, while the assessment of the experience at that destination itself may influence and modify the image. This demonstrates that perception and tourist satisfaction are vital in positioning a certain destination.

Hence, understanding the perception of tourists and expectation of local players is a major challenge for the industry in this dynamic 
market. It is an important issue in view of the fact that consumers are increasingly knowledgeable and capable of understanding and comparing the services provided, and it is, therefore, vital for industry players to recognize what their customers expect of them to stay competitive in the market.

Quality of service is a major differentiator. It attracts and retains the attention of consumer (Khuong \& Phuong, 2017) and should be strategically handled for competitive advantage (Boo, 2006). Assaker et al. (2016) classified service sector assessment into internal and external dimensions. External measurement is to measure the internal operation, while external measurement measures the quality of customer satisfaction-based goods or services. Nevertheless, external customer loyalty is the key factor of efficiency in service organizations.

\section{Service Quality Perception}

Throughout time, the standard of service offered at a tourist destination will become well known. Quality of service helps to define consumer desires and concerns; otherwise, consumers will feel disappointed (Russell, 2005). Service quality is a term that has created considerable interest and debate in literature due to difficulties in identifying and evaluating it (Wisniewski, 2001). Researchers have tried to describe the standards of service in several ways. Lee et al. (2011) and Parasuraman et al. (1985) described service quality as a contrast of customer expectations and their perception of the service actually provided. Kock et al. (2017) described the quality of service as a relativistic and cognitive discrepancy between experiential norms and benefits performance. Service quality is seen as an attitude which also represents a long-run overall assessment (Cronin \& Taylor, 1994; Hoffman \& Bateson, 2001).

For optimum results, service quality is thus managed through regular monitoring. Treating the workforce well may help improve service quality in ways that enhance the clients' level of satisfaction (Salleh et al., 2003). A study by Longenecker and Scazzero (2000) showed that human factors, such as teamwork and cooperation between management staff, are important for improving quality, especially in the service industry. They stated that factors like assessment of current practices and leadership are equally important in managing the quality of service. Additionally, internal performance is also enhanced because it reflects the actual quality of service. In other words, customer satisfaction is linked to the quality of service (Jamali, 2007).

There are different concepts of service quality, and two most widely accepted are the SERVQUAL model (Parasuraman et al., 1988) and Technical/Functional Quality framework (Gronroos, 1983; 1990). The SERVQUAL model is based on the interpretation of qualitative data from extensive explanatory research carried out in four service enterprises. Although SERVQUAL is widely used to measure consumer perception on quality, it has been criticised for several weaknesses. Research conducted in a variety of settings suggest that the five SERVQUAL dimensions are not universal and applicable to all services, and probably unnecessary to administer expectations whenever the model is administered (Babakus \& Boller, 1992; Carman, 1990; Parasuraman et al., 1991).

Cronin and Taylor (1992) claimed that a psychometrically superior assessment of the quality of service is obtained through the performance items of SERVQUAL alone. Recent researchers are integrating other constructs and measures along with the SERVQUAL dimensions to extend and improve the explanatory power of this model (Lassar et al., 2000). Ries and Trout (1981) stated that the concept of positioning applies to a company, service person or place and this is in sync with the concept of a product, which is defined as physical goods, service, place, person or idea (Kotler, 2000), Jamaludin et al. (2012) believes that positioning a destination is a process of establishing a distinctive place of that destination in the mind of potential customers. For effective destination positioning, the perception of the 
visitors must first be identified. Examining what is in the customers' mind can therefore provide guidance and help to decide the positioning strategy for the destination (Ibrahim and Gill, 2005).

\section{Conceptual Framework of Study}

Based on the proposed framework in Figure 1, the following hypotheses have been developed.

H1: There is significant relationship between service quality and local tourist satisfaction;

$\mathrm{H} 2$ : There is significant relationship between outdoor activities and local tourist satisfaction;

H3: There is significant relationship between scenery and local tourist satisfaction;

H4: There is significant relationship between place and local tourist satisfaction; and,

H5: There is significant relationship between motive of interest and local tourist satisfaction.

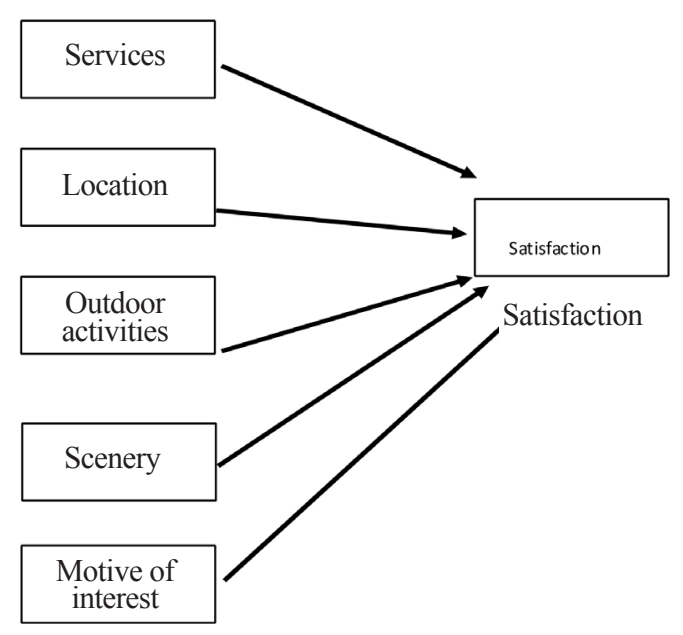

Figure 1. Proposed framework to study the satisfaction of local tourists on rural tourism products in Gunung Mulu National Park, Sarawak, Malaysia

\section{RESEARCH METHODOLOGY}

\section{Research Design}

This study used a quantitative approach to analyse data on service, outdoor activities, scenery, place and motive of interest. Reliability, replication and validity were the main considerations when selecting a data collection and analysis framework.

\section{Steps in Conducting Research}

In this research, three objectives were proposed to study the local tourist satisfaction on rural tourism products in Gunung Mulu National Park, Miri, Sarawak. Their experience and the motive that drove them to choose rural tourism were noted. Data was collected from 500 local tourists who visited Gunung Mulu National Park from March 2020 until XXXX. The respondents were instructed to complete a questionnaire via Google Form.

\section{Questionnaire Design}

A preliminary questionnaire was first developed based on items of the five elements of tourist satisfaction in Figure 1 that could be measured, which were generated from literature review.

The questionnaire was finalised after being configured to examine the hypotheses across all constructs of the proposed model. Respondents were asked to indicate their degree of agreement with each item for each construction in a fivepoint Likert scale (1-strongly disagree and 5 -strongly agree). The questionnaire contained two sections. The first section queried the respondents' demography, such as age, occupation and gender. The second section contained the model constructs in Figure 1 to determine the respondents' level of agreement/ disagreement.

\section{Data Analysis}

The sampling process was divided into two categories - probability sampling and snowball sampling. Analysis of data is a method where 
the raw questionnaire set transforms into usable information (Kumar et al., 2013). It is a profoundly significant move that leads to the study's progress. The invalid questionnaire will be deleted and discarded after the questionnaire surveys are done. The IBM SPSS version 25 software (IBM Corp, Armonk, NY, USA) was used to analyse the data collected from the respondents. Descriptive statistics were presented as mean $\pm \mathrm{SD}$. The Cronbach's alpha was calculated to determine the respondents' test score reliability.

\section{Conclusion}

This concept paper gives a general review of a framework that integrates tourist satisfaction and service quality. The model will provide a new perspective in the integration of rural tourism and tourist satisfaction, in Gunung Mulu National Park. The findings offer important implications for tourism stakeholders to manage their businesses by understanding the perception of local tourists on rural sustainable tourism,

This research contributes to extend knowledge in sustainable tourism destination in the context of emerging markets, especially for the Gunung Mulu National Park. It examined the satisfaction level of local tourists on service quality in a rural sustainable tourism destination. The model will provide new perspectives in the integration of tourist satisfaction and the intention to repeat their visit.

Malaysia continues to face challenges in providing high-quality services to tourists. This paper has proposed a conceptual model to better explain a causal relationship between constructs of local tourist satisfaction. It has extended the knowledge in rural sustainable tourism of Gunung Mulu National Park, which is considered an emerging market in world tourism. The findings may be used by local authorities, hotel and tourism operators to produce better policies and improve their services to suit the demand of local tourists and encourage them to repeat their visit. This will eventually build a sustainable industry that can raise the socio-economic status of the local community in Gunung Mulu.

\section{Acknowledgements}

The authors gratefully acknowledge the journal coordinators and committee for their encouragement and valuable assistance in publishing this paper.

\section{References}

Baker \& Crompton, (2000). Affective images of tourism destination. Journal of Travel Research, 35(4), 11 - 15.

C. Wang \& M. Hsu (2010). The relationship of destination image, satisfaction and behavioral intention: An integrated model. Journal of Travel and Tourism Marketing, 27(8), 829-843.

D. Gill, B. Byslma, \& R. Ouschan. (2007). "Customer perceived value in a cellar door visit: The impact on behavioural intentions. International Journal of Wine Business Research, 19(4), 257-275.

D. Godes \& D. Mayzlin. (2004). Using online conversations to study word-of-mouth communication. Marketing Science, 23(4), 545-560.

Echtner, C. M., \& Ritchie, J. R. B. (2003). “The meaning of measurement of destination image". Journal of Tourism Studies, 14(1), $37-48$.

De Vos, J., \& Witlox, F. (2017). Travel satisfaction revisited. On the pivotal role of travel satisfaction in conceptualising a travel behaviour process. Transportation research part A: policy and practice, 106, 364-373.

E. Bigné, I. Sánchez, and S. Sanz, "The functional-psychological continuum in the cognitive image of a destination: A confirmatory analysis,"Tourism Management, vol. 30, no. 5, pp. 1-9, 2009.

G. Assaker, V. E. Vinzi, \& P. O Connor. (2011). Examining the effects of novelty seeking, satisfaction, and destination image on tourists return pattern: A two factor, non-linear latent growth model. Tourism Management, 32(4), 890-901. 
Gallarza, M. G., Saura, I. G., \& Garcia, H. C. (2002). Destination image: Towards a conceptual framework. Annals of Tourism Research, 29(1), 56 - 78.

Hanafiah, M. H., \& Zulkifly, M. I. (2019). Tourism destination competitiveness and tourism performance. Competitiveness Review: An International Business Journal.J. C. Sweeney and G. N. Soutar, "Consumer perceived value: The development

J. E. Bigné, M. I. Sánchez, \& J. Sanchez. (2001). Tourism image, evaluation variables and after purchase behavior: Inter-relationship. Tourism Management, 22, 607-616

Kassim, M. N. (2001). Determinants of customer satisfaction and retention in the cellular phone market of Malaysia. Unpublished $\mathrm{PhD}$, South Cross University, Australia.

Kozak, M. (2001). Repeaters' behavior at two distinct destinations. Annals of Tourism Research, 28(3), 784 - 807.

Kock, F., Josiassen, A., \& Assaf, A. (2017). A dual process approach to understand tourists' destination choice processes.

Kislali, H., Kavaratzis, M., \& Saren, M. (2019). Destination image formation: Towards a holistic approach. International Journal of Tourism Research.

Kumar, V., \& Shah, D. (2004). Building and sustaining profitable customer loyalty for the $21^{\text {st }}$ Century. Journal of Retailing, 80, $317-330$.

Khuong \& Phuong, (2017). "The effects of destination image, perceived value and service quality on tourist satisfaction and word-of-mouth: A study in Ho Chi Minh City, Vietnam. International Journal of Trade, Economic \& Finance, 8(5).
Kock, F., Josiassen, A., \& Assaf, A. (2017). a dual process approach to understand tourists' destination choice processes.

M. Jamaludin, S. Johari, A. Aziz, K. Kayat, \& A. R. M. (2012). Yusof, "Examining structural relationship between destination image, tourist satisfaction and destination loyalty. International Journal of Independent Research and Studies, 1(3), 89-96.

M. N. Khuong \& P. D. Luan, "Factors affecting touristse satisfaction towards Nam Cat Tien National Park, Vietnam-A mediation analysis of perceived value. International Journal of Innovation, Management and Technology, 6, (4), 238-243, 2015.

N. H. M. Salleh, R. Othman, T. Sarmidi, K. Zakaria, B. A. Talib, \& S. H. M. Idris. (2014). Tourist satisfaction and loyalty of Kapas Island Marine Park: A Structural Equation Model (SEM) analysis. Indian Journal of Geo-marine Science, 43(9).

Shankar, V., Smith, A. K., \& Rangaswamy, A. (2003). Customer satisfaction and loyalty in online and offline environments. International Journal of Research in Marketing, 20, 153 - 175.

Lee, S., Jeon, S., \& Kim, D. (2020). The impact of tour quality and tourist satisfaction on tourist loyalty: The case of Chinese tourists in Korea. Tourism Management, 32(5), 1115-1124, 2011.

Tasci, A. D. A., \& Gartner, W. C. (2007). Destination image and its functional relationships. Journal of Travel Research, 45(4), 413 - 425. 